\title{
Solvent-free Hydrodeoxygenation of $\gamma$-Nonalactone on Noble Metal Catalysts Supported on Zirconia
}

\author{
José Luis González Escobedo ${ }^{1}$ (1) Eveliina Mäkelä ${ }^{1}$ (1) $\cdot$ Aki Braunschweiler $^{1,3} \cdot$ Juha Lehtonen $^{1,3} \cdot$ Marina Lindblad $^{2}$. \\ Riikka L. Puurunen ${ }^{1} \cdot$ Reetta Karinen ${ }^{1}$
}

Published online: 20 March 2019

(c) The Author(s) 2019

\begin{abstract}
The possibility to valorize levulinic acid (LA) dimers to lignocellulose-based biofuels via hydrodeoxygenation (HDO) was assessed using $\gamma$-nonalactone (GNL) as a model compound. Catalytic HDO experiments were performed in a batch reactor at $280{ }^{\circ} \mathrm{C}$ and at an average pressure of $57.5 \mathrm{bar} \mathrm{H}_{2}$. Noble metal ( $\mathrm{Ru}, \mathrm{Rh}, \mathrm{Pd}$, and $\mathrm{Pt}$ ) catalysts supported on $\mathrm{ZrO}_{2}$. All the catalysts were active in removing oxygen from the reactant. However, the most selective catalyst for hydrocarbons (24\%) was ruthenium. Unlike the other tested catalysts, Ru also provided branched hydrocarbons. In view of Ru's comparatively high selectivity to hydrocarbons, it was tested at various reaction temperatures $\left(220-280^{\circ} \mathrm{C}\right)$ for $300 \mathrm{~min}$. The experiments at lower temperatures resulted in less hydrocarbons and more intermediate products, such as alcohols. In total, nearly 70 products were identified, and some of the reactions that likely occurred in the HDO experiments were discussed. The production of hydrocarbons from GNL highlights the potential of LA dimers as a route to lignocellulose-based biofuels.
\end{abstract}

Keywords Levulinic acid dimer $\cdot \gamma$-Nonalactone $\cdot$ Hydrodeoxygenation $\cdot$ Noble metal $\cdot$ Hydrocarbon $\cdot$ Fuel

\section{Introduction}

Concerns regarding climate change and the insufficiency of fossil-based materials have directed the attention of research towards bio-based alternatives [1]. One of these alternatives is lignocellulose, which is considered as an abundant resource for replacing fossil-based fuels [2]. The raw materials derived from lignocellulose, which contain many

José Luis González Escobedo and Eveliina Mäkelä contributed equally to this work.

Electronic supplementary material The online version of this article (https://doi.org/10.1007/s11244-019-01161-6) contains supplementary material, which is available to authorized users.

José Luis González Escobedo

jose.gonzalezescobedo@aalto.fi

$\triangle$ Eveliina Mäkelä

eveliina.makela@aalto.fi

1 Department of Chemical and Metallurgical Engineering, Aalto University, P.O. Box 16100, 00076 Aalto, Finland

2 Neste Corporation, P.O. Box 310, 06101 Porvoo, Finland

3 Present Address: VTT Technical Research Centre of Finland LTD, P.O. Box 1000, 02044 VTT, Finland functional groups, can be transformed into various chemical intermediates and final products [3]. Levulinic acid (LA), in addition to furfural, is one of the most important platform chemicals [4-6], which can be produced from lignocellulosic sugars: hexoses or pentoses [5].

LA, a $\gamma$-keto-carboxylic acid $\left(\mathrm{C}_{5} \mathrm{H}_{8} \mathrm{O}_{3}\right)$, is highly reactive and has several applications as a specialty chemical in agriculture, chemical industry, and in the food industry [7]. $\gamma$-Valerolactone (GVL) is an important chemical produced from LA via homogeneous (e.g. $\mathrm{RuCl}_{2}\left(\mathrm{PPh}_{3}\right)_{3}$ ) or heterogeneous (e.g. $\mathrm{Ru} / \mathrm{C}$ ) catalysis [8]. Recently, the catalytic conversion of GVL to fuels has been studied [8]. So far, the target has been to produce bio-based oxygenates to be blended with gasoline. For example, the production of 2-methyltetrahydrofuran (MTHF), which can be blended with gasoline, has been reported by Bozell et al. [9]. Hydrocarbons are usually considered undesired products in the hydrodeoxygenation (HDO) of GVL, because the carbon chain is too short for transportation fuels. In fact, heavier hydrocarbons are necessary for bio-based jet fuel or diesel [10]. Converting GVL to pentenoic acid offers at least two possible routes to heavier hydrocarbons [8].

Bond et al. [11] studied the ring-opening of GVL to pentenoic acid, which in turn was decarboxylated to butenes. 
Butenes were further oligomerized to higher alkanes [12]. Another route to alkanes proceeded via pentenoic acid hydrogenation to pentanoic acid [13, 14], which was ketonized to 5-nonanone and finally deoxygenated to alkanes [15]. Moreover, the aldol condensation of various lignocellulose-derived carbonyl compounds to form larger molecules (up to $\mathrm{C}_{15}$ ) has been studied recently [3]. These compounds can be subsequently converted into diesel fuel components [16]. For the LA platform, aldol condensation into LA dimers was first described by Blessing et al. [17]. This route was further explored recently by Käldström et al. [18]. The aldol condensation of LA was performed in hydrogenating conditions in the presence of a strong cation exchange resin containing palladium. The products were mostly $\mathrm{C}_{10}$, branched dimers containing carboxyl, carbonyl, and lactone moieties [18]. These dimers might be a suitable feedstock for HDO in order to obtain hydrocarbons.

$\gamma$-Nonalactone (GNL) is a $\mathrm{C}_{9}$ compound having two oxygen atoms. It can be considered as a model compound for LA dimers, representing the lactone moieties present in them. Because the preservation of the dimers' carbon chains is desired, the study of a compound with a long sidechain is relevant. In biofuel production, HDO is used to increase the energy density of the feed by removing oxygen as water [19]. To our knowledge, GNL has not been studied in HDO, although it is analogous to GVL.

Conventional HDO is performed with sulfided catalysts, such as NiMo and $\mathrm{CoMo}$ on $\mathrm{Al}_{2} \mathrm{O}_{3}$, which require sulfur replenishing. However, sulfur from this process contaminates the product, requiring additional processing for sulfur removal [19]. Another option is to utilize bifunctional noble metal catalysts, which are known for their ability to activate and eliminate the carbonyl, as experienced by fatty acids and their esters [20]. They have also been found to be active in the HDO of lignin-derived guaiacol [21]. By using a less acidic support than conventional $\gamma-\mathrm{Al}_{2} \mathrm{O}_{3}$, such as $\mathrm{ZrO}_{2}$, excess coking could be prevented [20].

In this work, the HDO of GNL was studied as a model compound for LA dimers using noble metal catalysts supported on $\mathrm{ZrO}_{2}$. The goal was to obtain components suitable for transportation fuels and to minimize the yield of oxygenates. A possible reaction network is discussed, including a diester compound that has not been reported previously in the context of lactone HDO.

\section{Experimental Section}

\subsection{Materials}

Reagents purchased from Sigma-Aldrich were utilized without further purification including GNL (98\%), 2-butanol (99\%), 2-propanol ( $\geq 99.5 \%)$, 3-octanone ( $\geq 98 \%$ ), octanoic acid ( $\geq 99 \%$ ), 3-octanol (99\%), octane (analytical standard), nonanoic acid (98\%), methyl nonanoate ( $\geq 97 \%$ ), 4-nonanone (sold 'AS IS' without purity identification), 1-nonanol (98\%), nonane (analytical standard), hexanoic acid ( $\geq 99 \%)$, hexane ( $\geq 95 \%$ ), heptanoic acid (96\%), heptane (anhydrous, $99 \%$ ) and $n$-methyl- $n$-trimethylsilylfluoroacetamide (98.5\%). 4-Nonanol [Assay (GC, area\%): $\geq 96.5 \%$ (a/a)] and 2-heptanone ( $\geq 98 \%$ ) were purchased from Merck KGaA and acetonitrile (99.9\%) and formic acid (99\%) from VWR Chemicals, and these chemicals were also utilized without further purification. The chemicals used in the Karl-Fisher titration were: Merck's Apura ${ }^{\circledR}$ two component titrant containing $\mathrm{MeOH}$ and iodine, Merck's Apura ${ }^{\circledR}$ solvent for volumetric Karl-Fisher titration containing $\mathrm{MeOH}$ and imidazole, and Merck's Apura ${ }^{\circledR}$ water standard $\left(1 \% \mathrm{H}_{2} \mathrm{O}\right)$.

All gases were purchased from Oy AGA Ab including hydrogen utilized in the HDO experiments (purity 5.0) and gases required for the various analytical techniques: hydrogen (purity 5.0), helium (purity 4.6), argon (purity 5.0), synthetic air (purity 5.0), oxygen (purity 5.0) and nitrogen (purity 5.0). Two calibration gas mixtures from $\mathrm{Oy}$ AGA Ab were utilized. The first contained $40 \mathrm{~mol} \%$ nitrogen, $5 \mathrm{~mol} \%$ methane, $10 \mathrm{~mol} \%$ ethane, $5 \mathrm{~mol} \%$ ethene, $10 \mathrm{~mol} \%$ propane, $5 \mathrm{~mol} \%$ propene, $5 \mathrm{~mol} \%$ acetylene, $10 \mathrm{~mol} \%$ butane and $10 \mathrm{~mol} \%$ isobutene. The second contained $15 \mathrm{vol} \% \mathrm{car}-$ bon monoxide, 15 vol\% carbon dioxide, 15 vol\% hydrogen, $40 \mathrm{vol} \%$ nitrogen and $15 \mathrm{vol} \%$ methane.

Monoclinic $\mathrm{ZrO}_{2}$ from Saint-Gobain NorPro was used as a catalyst support. Metal precursors were purchased from Sigma-Aldrich [Rh(III) nitrate solution (10 $\mathrm{wt} \% \mathrm{Rh}$ in $>5 \mathrm{wt} \% \mathrm{HNO}_{3}$ )], Alfa Aesar [Pt(IV) nitrate solution (15 wt\% Pt) and Pd(II) nitrate solution (12-16 wt\% Pd)] and Acros Organics [Ru(III) chloride hydrate (35-40 wt \% Ru)].

\subsection{Catalyst Preparation}

The $\mathrm{ZrO}_{2}$ support was ground, sieved to $0.25-0.42 \mathrm{~mm}$, and calcined in synthetic air at $600{ }^{\circ} \mathrm{C}$ for $10 \mathrm{~h}$. The metal catalysts (nominally $3 \mathrm{wt} \%$ ) were prepared by incipient wetness impregnation using appropriate amounts of aqueous solutions of metal precursors. For this purpose, the pore volume of the support was estimated by its water uptake capacity, which was approximately $40 \mathrm{wt} \%$. During the impregnation, the precursor solution was added drop by drop and mixed with a spatula. Several batches were prepared with a typical size of $3 \mathrm{~g}$. After impregnation, the catalysts were dried at room temperature for $5 \mathrm{~h}$ and in an oven at $100{ }^{\circ} \mathrm{C}$ overnight. The prepared catalysts were thermally treated $\left(300{ }^{\circ} \mathrm{C}\right)$ under synthetic air flow of $100 \mathrm{~mL} / \mathrm{min}$ for $3 \mathrm{~h}$ (heating rate $30{ }^{\circ} \mathrm{C} / \mathrm{h}$ ). The catalysts' particle size was assumed to be the same as for the support after impregnation. In the case of the $\mathrm{Ru}$ catalyst, the chloride from the precursor could not 
be fully removed during heat treatment and reduction (see Sect. 4).

\subsection{Catalyst Characterization}

\subsubsection{X-ray Fluorescence}

The metal loadings of the prepared catalysts were analyzed by X-ray fluorescence (XRF). Each sample was ground and pressed into a tablet using Boreox $®$ binder and an aluminum cup. The measurements were performed with a Rigaku ZSX Primus wavelength dispersive spectrometer.

\subsubsection{X-ray Diffraction}

X-Ray diffraction (XRD) analysis to detect the crystallographic phases present on the support oxide and the metal catalyst was executed with a PANalytical X'Pert PRO MPD Alpha-1 diffractometer with $\mathrm{Cu} \mathrm{K} \alpha 1$ radiation $(45 \mathrm{kV}$ and $40 \mathrm{~mA}$ ) for the fresh catalysts. The X-ray scanning range was $4.5^{\circ}-120^{\circ}(2 \theta)$ with a step of $0.0131^{\circ}$. The samples were ground for the analysis.

\subsubsection{Physisorption}

Isothermal $\left(-196{ }^{\circ} \mathrm{C}\right)$ nitrogen physisorption measurements in liquid nitrogen were performed using a Thermo Scientific's Surfer equipment. Specific surface areas were calculated from adsorption isotherms according to the Brunauer-Emmett-Teller theory (BET) [22]. The total pore volume and average pore diameter were calculated based on the Barrett-Joyner-Halenda method (BJH) [23]. Prior to the $\mathrm{N}_{2}$ adsorption, each catalyst sample (about $300 \mathrm{mg}$ ) was weighed in a quartz tube and evacuated in elevated temperature $\left(200{ }^{\circ} \mathrm{C}, 3 \mathrm{~h}\right)$ in order to remove any adsorbed components and moisture. For the spent catalyst, the evacuation was performed at lower temperature $\left(120^{\circ} \mathrm{C}, 5 \mathrm{~h}\right)$ to avoid the burning of the possible carbonaceous material formed in the experiment.

\subsubsection{Chemisorption}

Active metal dispersion and average metal particle size were calculated from the chemisorption of hydrogen or carbon monoxide using a Thermo Scientific's Surfer equipment. Each sample (about $300 \mathrm{mg}$ of fresh, calcined catalyst or spent, washed catalyst after experiment) was weighed in a U-shaped quartz tube and supported with quartz glass wool. Prior to the measurements, the samples were reduced in hydrogen flow at $290{ }^{\circ} \mathrm{C}$ for $3 \mathrm{~h}$. Afterwards, degassing down to pressure $10^{-5}$ Torr was performed under the same temperature for $2 \mathrm{~h}$. Adsorption measurements were performed at $35^{\circ} \mathrm{C}$ except with Ru catalyst $\left(75^{\circ} \mathrm{C}\right)$ as suggested by Shen et al. [24] CO was chosen as probe molecule for $\mathrm{Pt}$ to avoid hydrogen spillover and for Pd to avoid bulk hydride formation [25], and it was also used for $\mathrm{Rh}$. For $\mathrm{Ru}, \mathrm{H}_{2}$ was selected as suggested by Shen et al. [24] Two chemisorption isotherms were measured: the first of the total adsorption and the second of the reversible adsorption. Degassing the sample down to pressure $10^{-5}$ Torr was performed isothermally between the two measurements to remove all reversibly adsorbed gas. The irreversibly adsorbed monolayer volume was obtained from the linear regression of the subtracted isotherm to zero pressure from which the dispersion and particle size were calculated [25]. The metal particles were assumed to be spherical, and the adsorption stoichiometry was assumed to be two for $\mathrm{H}_{2}$. For $\mathrm{CO}$, the adsorption stoichiometry is more controversial, but an approximation of $\mathrm{CO}$ and metal stoichiometry of 1:1 has been widely used for noble metals in previous studies as listed in the Handbook of Heterogeneous Catalysis [25], and was also adopted in this work.

\subsubsection{Scanning Transmission Electron Microscopy}

Scanning transmission electron microscopy (STEM) images were taken from the fresh and spent catalysts to estimate the average size of the metal nanoparticles deposited on the support before and after the experiment. A JEOL JEM-2200FS high resolution microscope was used at $200 \mathrm{kV}$ acceleration voltage and with magnifications from $3 \times 10^{6}$ to $8 \times 10^{6}$. Energy-dispersive X-ray spectroscopy (EDS) was applied alongside with STEM to detect the chemical elements present in the sample. STEM images were used to measure particle diameters. The numbers of measured particles were 84 for ruthenium, 59 for rhodium, 49 for palladium, and 198 for platinum. In the case of the spent catalysts, 328 particles were measured for $\mathrm{Ru}, 355$ for $\mathrm{Rh}, 380$ for $\mathrm{Pd}$, and 646 for Pt. Statistical inferences were applied to estimate the sampling error, as described in Online Resource.

\subsubsection{Thermogravimetric Analysis}

The amount of solids deposited on the catalysts during HDO reactions was determined by thermogravimetric analysis (TGA) for the spent catalysts. Tests were performed in a TA Instruments' TGA Q500 equipment. Around $20 \mathrm{mg}$ of spent, unwashed catalyst was dried in pure nitrogen ramping from room temperature up to $250{ }^{\circ} \mathrm{C}$ at $10{ }^{\circ} \mathrm{C} / \mathrm{min}$ (GNL boiling point $243{ }^{\circ} \mathrm{C}$ ). The ramp was followed by a $5 \mathrm{~min}$ hold at $250{ }^{\circ} \mathrm{C}$. Afterwards, the same procedure was repeated up to $900{ }^{\circ} \mathrm{C}$ on the dried sample with pure oxygen. 


\subsection{HDO Experiments}

HDO experiments were performed in a three phase system, solvent-free, and with the catalyst forming a slurry with the liquid. A $100 \mathrm{~mL}$ batch reactor by Parr was used. Before each experiment, $0.6 \mathrm{~g}$ of catalyst was placed in the reactor and dried in nitrogen at $180^{\circ} \mathrm{C}$. After $1 \mathrm{~h}$, the vessel was flushed with $\mathrm{N}_{2}$ and cooled to $30^{\circ} \mathrm{C}$. Then, the catalyst was reduced in $20 \mathrm{bar}_{2}$ at $290{ }^{\circ} \mathrm{C}$ for $1 \mathrm{~h}$ (the degree of catalyst reduction was not checked before experiment) while stirring at $200 \mathrm{rpm}$; afterwards, the reactor was cooled to room temperature and vented to atmospheric pressure. For HDO, the reactor was heated to reaction temperature prior to adding $23 \mathrm{~mL}$ (22.0-22.2 g) of GNL and pressurizing the reactor to $60 \mathrm{bar}_{2}$. During HDO, the reactor was stirred at $700 \mathrm{rpm}$. $\mathrm{H}_{2}$ was replenished periodically, every time the pressure had decreased to 55 bar, in order to maintain an average pressure of $57.5 \mathrm{bar}$. After the experiment, the reactor was cooled to room temperature with the aid of a water bath. Then, a gas sample was taken and the reactor was vented and opened for the recovery of the liquid and the spent catalyst. Finally, the product mixture was analyzed. The mass balances typically closed with a loss of 5 to $10 \%$. Calculated carbon balances for each experiment are reported in the Online Resource Table S5.

The products were characterized by various chromatographic techniques, elemental analysis, and Karl-Fischer titration. The basis of calculation for GNL and $\mathrm{H}_{2}$ conversion, product selectivities, and yields are presented in the Online Resource.

\subsection{Product Analytics}

\subsubsection{Organic Phase}

The components in the organic products were identified using an Agilent gas chromatograph (GC) equipped with a Zebron ZB-wax Plus column $(60 \mathrm{~m} \times 0.25 \mathrm{~mm} \times 0.25 \mu \mathrm{m})$ and a mass spectrometer (GC-MS, 7890-5975). The injection of $1 \mu \mathrm{L}$ sample was done at $250{ }^{\circ} \mathrm{C}$ with $0.6 \mathrm{~mL} / \mathrm{min}$ flow and 80:1 split ratio. The temperature program started with a 2 min hold at $60{ }^{\circ} \mathrm{C}$, followed by heating at $7{ }^{\circ} \mathrm{C} / \mathrm{min}$ until $160{ }^{\circ} \mathrm{C}$ with a $3 \mathrm{~min}$ hold, and finally, at $5{ }^{\circ} \mathrm{C} / \mathrm{min}$ to $200{ }^{\circ} \mathrm{C}$ with a 6 min hold. The electron impact ionization MS detector was operated at $70 \mathrm{eV}$, with a quadrupole scan range of 30-500 amu. The NIST MS library was used to aid spectral interpretation.

The products were quantified by GC (HP 6890 Series) with flame ionization detector (FID). The GC column and method were identical to the ones used for GC-MS. Because of an overlapping product peak (octanoic acid) with the GNL peak, a second GC with a Sigma-Aldrich Supelco ${ }^{\circledR}$ SLB-IL111 hyper-polar fused silica capillary column $(30 \mathrm{~m} \times 0.25 \mathrm{~mm} \times 0.2 \mu \mathrm{m})$ was used for GNL conversion calculations. Using the same GC method, the hyper-polar column provided a clean GNL peak, but, unlike the ZB-wax column, it did not separate the hydrocarbons. For calibration of GNL and most products, the internal standard was 2-propanol. Not all the product compounds were commercially available, and the response factors for those components were estimated according to the effective carbon number method originally proposed by Scanlon and Willis [26]. The quantification of octanoic acid was achieved by operating the GC-MS system in the selected ion monitoring (SIM) mode. Ions 6.10 and 73.10, found only in the octanoic acid spectrum, were used to extract an independent peak, which was calibrated as for the rest of the components.

In the GNL experiments, water was formed as a HDO product. In all experiments, the organic phase contained dissolved or colloidal water. The water in the organic phase was analyzed using a SI Analytics' volumetric Karl-Fisher titrator (TitroLine $7500 \mathrm{KF}$ ). Prior to measurements, a water standard was used to calibrate the concentration of the titrant.

The elemental compositions of the organic phases were analyzed using a Perkin Elemer 2400 Series II elemental analyzer. Elemental compositions were used to build a van Krevelen diagram [27].

During the experiments, heavy condensation products could be formed that were nonvolatile and thus not detected with GC-MS. Heavier compounds were qualitatively identified with liquid chromatography (LC) using an Agilent 1260 HPLC-system coupled to an Agilent 6530 QTOF mass spectrometer. Moreover, some compounds that were abundant according to GC, and could not be identified with sufficient certainty using only the NIST MS library, were also searched using LC. The samples were diluted to 30/70 wt\% MilliQ water/acetonitrile (ACN) solution, and the final concentration of each sample was approximately $100 \mathrm{ppm}$. The injection volume was $20 \mu \mathrm{L}$, and the eluent was 20/80 wt $\%$ MilliQ water/ACN solution $+0.1 \mathrm{wt} \%$ formic acid with a flow rate of $0.25 \mathrm{~mL} / \mathrm{min}$. A Kinetex Biphenyl column $(2.6 \mu \mathrm{m} \times 100 \mathrm{~mm} \times 2.1 \mathrm{~mm})$ or a Luna Omega PS-C18 column $(100 \times 2.1 \mathrm{~mm}, 3 \mu \mathrm{m})$ with positive mode of electrospray ionization (+ESI) were utilized in the mass range of 50-1000 amu for the total ion current. For searching individual compounds, the extract ion chromatograms for selected molecular masses were recorded. Finally, the mass spectrum of a compound was obtained using an Agilent MassHunter software with a Find by Formula (FBF) algorithm that searched the expected molecular formulas with a maximum of $5 \mathrm{ppm}$ difference to the calculated value.

The silylation of the organic samples was also attempted to reveal possible nonvolatile compounds. The silylation was performed by mixing ca. $20 \mathrm{mg}$ of sample with $1 \mathrm{~mL}$ 
of $n$-methyl- $n$-trimethylsilylfluoroacetamide (MSTFA). The mixtures were left to room temperature overnight prior to analysis in a Thermo Scientific Trace 1300 ISQ having an Agilent J\&W HP-5 column $(60 \mathrm{~m} \times 0.25 \mathrm{~mm} \times 0.25 \mu \mathrm{m})$ with $\mathrm{He}$ as a carrier gas $(1 \mathrm{~mL} / \mathrm{min})$. The heating program started at $80{ }^{\circ} \mathrm{C}$ with a 1 min hold and continued to $300{ }^{\circ} \mathrm{C}$ $\left(15^{\circ} \mathrm{C} / \mathrm{min}\right)$ with a $1 \mathrm{~min}$ hold. The inlet temperature was $280^{\circ} \mathrm{C}$ and the injection volume $1 \mu \mathrm{L}$. The split ratios of 1:100 and 1:20 were attempted with a solvent delay.

\subsubsection{Gas Phase}

The product gas mixtures were analyzed after each experiment by an Agilent 6890 Series GC with a FID and a thermal conductivity detector (TCD). $\mathrm{CO}, \mathrm{CO}_{2}, \mathrm{H}_{2}$ and $\mathrm{N}_{2}$ were analyzed with the TCD connected to two columns: a HPPLOT/Q $(30 \mathrm{~m} \times 0.53 \mathrm{~mm} \times 40 \mu \mathrm{m})$ and a HP Molesieve $(30 \mathrm{~m} \times 0.53 \mathrm{~mm} \times 25 \mu \mathrm{m})$. Produced hydrocarbons were analyzed with the FID utilizing a HP-AL/KCL column $(50 \mathrm{~m} \times 0.32 \mathrm{~m} \times 8 \mu \mathrm{m})$. The GC was calibrated with an Oy AGA Ab calibration gas mixture which enabled quantitative analysis. The heating program started from $40^{\circ} \mathrm{C}$ with a $9.5 \mathrm{~min}$ hold, and the inlet temperature was $200^{\circ} \mathrm{C}$. The heating rate was $10{ }^{\circ} \mathrm{C} / \mathrm{min}$ until the final temperature of $200^{\circ} \mathrm{C}$ without any extra holds. The chromatographic analysis provided the molar composition of the gas phase. The amounts of the gases were calculated with this molar composition and the absolute pressure in the reactor at the time of the sampling (room temperature), assuming ideal gas.

\subsubsection{Aqueous Phase}

The produced water phase (if any) was separated using a separating funnel, and the total water was calculated as the sum of the separate aqueous phase and the water in the organic phase. The composition of the aqueous phase was qualitatively analyzed with an Agilent GC-MS equipment described earlier. In this case, the quadrupole scan range was $18-500 \mathrm{amu}$.

\section{Results}

\subsection{Characterization of Fresh Catalysts}

The nominal metal loading of the impregnated catalysts was $3 \mathrm{wt} \%$ in all cases. The values measured by XRF fell short by 0.5 to 0.3 percentage points (Table 1 ), except for palladium, for which the measured metal loading was $3.0 \mathrm{wt} \%$.

Physisorption and chemisorption results are presented in Table 1. The physisorption isotherms for fresh and spent catalysts are presented in Online Resource (Figure S1). The BET surface areas of the impregnated $\mathrm{Rh}, \mathrm{Pd}$, and Pt catalysts were similar compared to the pure $\mathrm{ZrO}_{2}$ support, but the surface area of the Ru catalyst was higher than for the support. The BJH pore volumes decreased during impregnation with $\mathrm{Rh}, \mathrm{Pt}$ and $\mathrm{Pd}$ and increased with $\mathrm{Ru}$. The average $\mathrm{BJH}$ pore diameters were between 10 and $13 \mathrm{~nm}$. The pore

Table 1 Textural properties of fresh and spent $\left(280^{\circ} \mathrm{C}, 30-40 \%\right.$ conversion) noble metal catalysts supported on zirconia

\begin{tabular}{|c|c|c|c|c|c|c|c|c|}
\hline \multirow[t]{2}{*}{ Catalyst } & \multicolumn{3}{|c|}{ Physisorption } & \multicolumn{3}{|l|}{ Chemisorption } & \multicolumn{2}{|l|}{ STEM } \\
\hline & $\mathrm{S}_{\mathrm{BET}}\left(\mathrm{m}^{2} / \mathrm{g}\right)$ & $\begin{array}{l}\text { Pore } \\
\text { volume } \\
\left(\mathrm{cm}^{3} / \mathrm{g}\right)\end{array}$ & $\begin{array}{l}\text { Average pore } \\
\text { diameter }(\mathrm{nm})\end{array}$ & $\begin{array}{l}\text { Irrevers- } \\
\text { ible adsorp- } \\
\text { tion capacity } \\
\left(\mu \mathrm{mol}_{\mathrm{gas}} / \mathrm{g}_{\mathrm{cat}}\right)\end{array}$ & Dispersion $(\%)$ & $\begin{array}{l}\text { Average } \\
\text { particle size } \\
(\mathrm{nm})\end{array}$ & $\begin{array}{l}\text { Average } \\
\text { particle size } \\
(\mathrm{nm})^{\mathrm{c}}\end{array}$ & $\begin{array}{l}\text { Relative standard } \\
\text { error of particle } \\
\text { size }(\%)^{\mathrm{d}}\end{array}$ \\
\hline $\mathrm{ZrO}_{2}$ & 64 & 0.27 & 11 & & & & & \\
\hline $\begin{array}{c}2.7 \mathrm{wt} \% \mathrm{Ru} / \\
\mathrm{ZrO}_{2}\end{array}$ & 80 & 0.32 & 10 & $15^{\mathrm{a}}$ & $11^{\mathrm{a}}$ & 8.0 & 1.5 & 6.1 \\
\hline $\begin{array}{l}2.5 \mathrm{wt} \% \mathrm{Rh} / \\
\mathrm{ZrO}_{2}\end{array}$ & 58 & 0.23 & 11 & $209^{b}$ & $87^{b}$ & 1.2 & 2.0 & 5.1 \\
\hline $\begin{array}{c}3.0 \mathrm{wt} \% \mathrm{Pd} / \\
\mathrm{ZrO}_{2}\end{array}$ & 64 & 0.26 & 11 & $60^{\mathrm{b}}$ & $21^{\mathrm{b}}$ & 5.3 & 2.9 & 8.7 \\
\hline $2.7 \mathrm{wt} \% \mathrm{Pt} / \mathrm{ZrO}_{2}$ & 65 & 0.22 & 13 & $52^{\mathrm{b}}$ & $37^{\mathrm{b}}$ & 2.7 & 1.9 & 3.2 \\
\hline $\mathrm{Ru} / \mathrm{ZrO}_{2}$ spent & 70 & 0.25 & 8 & $25^{\mathrm{a}}$ & $19^{\mathrm{a}}$ & 4.8 & 1.8 & 6.0 \\
\hline $\mathrm{Rh} / \mathrm{ZrO}_{2}$ spent & 54 & 0.22 & 9 & $35^{\mathrm{b}}$ & $15^{\mathrm{b}}$ & 7.4 & 4.8 & 4.0 \\
\hline $\mathrm{Pd} / \mathrm{ZrO}_{2}$ spent & 60 & 0.25 & 10 & $20^{\mathrm{b}}$ & $7.0^{\mathrm{b}}$ & 16 & 5.4 & 3.3 \\
\hline $\mathrm{Pt} / \mathrm{ZrO}_{2}$ spent & 71 & 0.28 & 10 & $31^{\mathrm{b}}$ & $23^{\mathrm{b}}$ & 4.5 & 3.8 & 2.7 \\
\hline
\end{tabular}

${ }^{\mathrm{a}} \mathrm{H}_{2}$ chemisorption, $75^{\circ} \mathrm{C}$

${ }^{\mathrm{b}} \mathrm{CO}$ chemisorption, $35^{\circ} \mathrm{C}$

${ }^{\mathrm{c}}$ Population means statistically inferred from STEM images

${ }^{\mathrm{d}}$ Based on a normal distribution with $95 \%$ confidence level 
size distributions of the fresh and spent catalysts are presented in the Online Resource (Figure S2).

Based on chemisorption, significantly different active metal dispersions $(11 \%-87 \%)$ were calculated for the catalysts. The Rh catalyst displayed the highest dispersion, whilst the Ru catalyst displayed the lowest. Particle sizes were determined based on both chemisorption and STEM images. A selection of the latter is presented in Online Resource (Figure S3). Because no metal particle peaks were discerned in the XRD diffractograms, it appeared that the metal particles were small and well dispersed (XRD's detection limit is $\sim 3 \mathrm{~nm}$ ) [28].

\subsection{Activity of Catalysts}

The HDO reactions were studied with the four noble metal catalysts at $280^{\circ} \mathrm{C}$ and 57.5 bar $\mathrm{H}_{2}$. For each catalyst, a series of experiments was performed with increasing reaction times from 15 to $300 \mathrm{~min}$. The GNL conversions as a function of reaction time are illustrated in Fig. 1. Additionally, plain $\mathrm{ZrO}_{2}$ support was tested in a 300 min experiment, providing $13.8 \%$ GNL conversion. At comparable GNL conversion levels (30-40\%), the $\mathrm{H}_{2}$ conversion was $\sim 80 \%$ with $\mathrm{Ru}$ and $\sim 20 \%$ with the other three metals. The initial turnover frequencies (see Online Resource), based on surface metal atoms from chemisorption, were $1 \mathrm{~s}^{-1}$ for $\mathrm{Ru}$, $0.2 \mathrm{~s}^{-1}$ for Rh, $0.7 \mathrm{~s}^{-1}$ for Pd, and $0.5 \mathrm{~s}^{-1}$ for Pt.

In addition to the catalytic experiments, 300 min blank, non-catalyzed experiments were performed at the same conditions as the other experiments. A blank performed before the catalyzed experiments resulted in $<2 \%$ conversion and

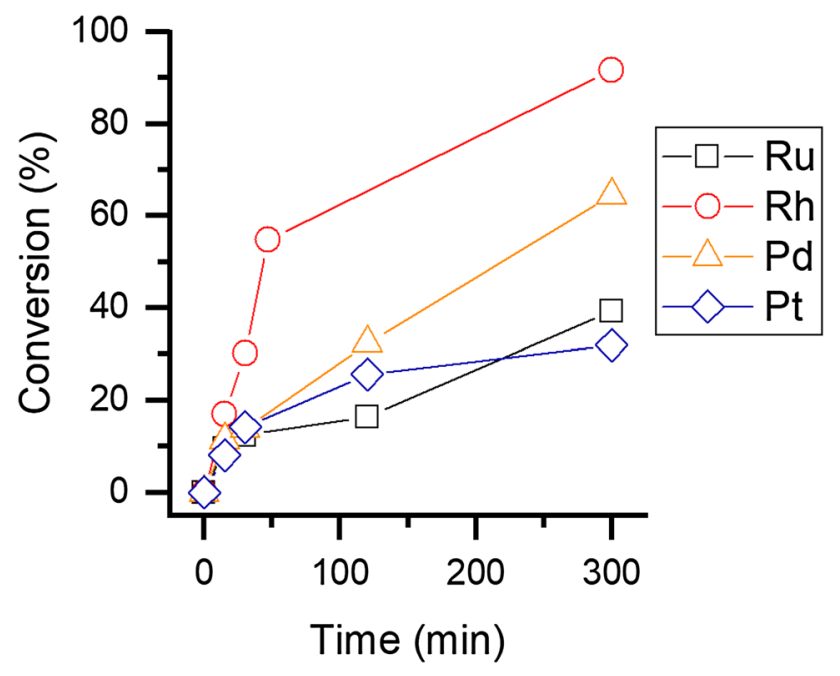

Fig. 1 GNL conversion as a function of reaction time. Reaction conditions: $0.6 \mathrm{~g}$ catalyst, $\sim 3 \%$ metal loading, $23 \mathrm{~mL}$ GNL (pure), $280{ }^{\circ} \mathrm{C}, 57.5$ bar $\mathrm{H}_{2}$. Note that the $\mathrm{Ru}$ catalyst contained chloride species

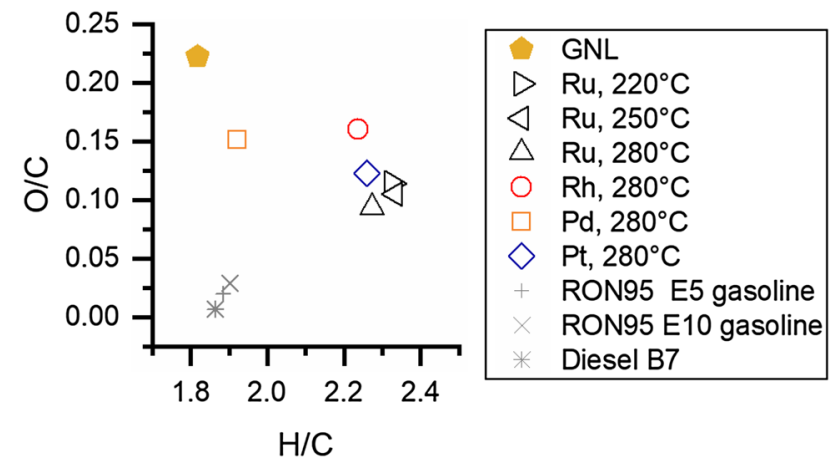

Fig. 2 van Krevelen diagram. Molar $\mathrm{H} / \mathrm{C}$ and $\mathrm{O} / \mathrm{C}$ of the organic liquid product mixtures obtained with $\mathrm{ZrO}_{2}$-supported catalysts compared to the reactant (GNL) and to standard fuels [29]. In the case of $280{ }^{\circ} \mathrm{C}$ reactions, the reported products were obtained at $30-40 \%$ GNL conversion. The values exclude unconverted GNL and water. Reaction temperature in legend. Note that the Ru catalyst contained chloride species

blanks performed afterwards resulted in $4-6 \%$ conversion. Negligible amounts of products were detected.

The van Krevelen diagram of the organic liquid products with similar conversion levels at $280^{\circ} \mathrm{C}$ (Fig. 2) provides an insight into the catalysts' HDO activity. When catalysts converted $30-40 \%$ of the feedstock, all of them eliminated some oxygen. However, the products still contained more oxygen than the amount allowed by fuel specifications [29]. On the other hand, the uptake of hydrogen was high with $\mathrm{Ru}, \mathrm{Rh}$, and $\mathrm{Pt}$. The H/C ratio of the product obtained with the Pd catalyst was lower than the H/C ratios of the products obtained with the other catalysts.

\subsection{Selectivity of Catalysts}

The product distributions obtained with each metal at $280{ }^{\circ} \mathrm{C}$ with similar conversions, 30-40\%, are presented in Fig. 3. The distributions include all the attained products in the gas, organic, and aqueous phases and the solids deposited on the catalyst during the experiment (from TGA). Because nearly 70 products were detected (Online Resource Table S1), they were categorized by functional groups. The total water in both liquid phases is reported. The aqueous phase was accounted as $100 \%$ water, although it contained traces of organic products (see below).

The Ru catalyst gave a significantly different product distribution compared to the other catalysts, especially Pd and Pt (Fig. 3). Ru had the highest selectivity to liquid hydrocarbons (close to $24 \%$ ), and it was the only metal producing branched hydrocarbons, although in minor amounts $(0.7 \%$ selectivity). Gaseous hydrocarbons, mainly methane, were also produced. Moreover, Ru was the only catalyst producing lactones with sidechains containing less than five carbons. 
Fig. 3 Grouped product selectivities obtained with the noble metal catalysts. GNL conversion $(X)$ is marked on top of the bars. Reaction conditions: $0.6 \mathrm{~g}$ catalyst, $\sim 3 \%$ metal loading, $23 \mathrm{~mL}$ GNL (pure), $280{ }^{\circ} \mathrm{C}, 57.5 \mathrm{bar}$ $\mathrm{H}_{2}$. The results were obtained after $300 \mathrm{~min}, 30 \mathrm{~min}, 120 \mathrm{~min}$ and $300 \mathrm{~min}$ for $\mathrm{Ru}, \mathrm{Rh}, \mathrm{Pd}$ and Pt catalysts, respectively. Note that the Ru catalyst contained chloride species

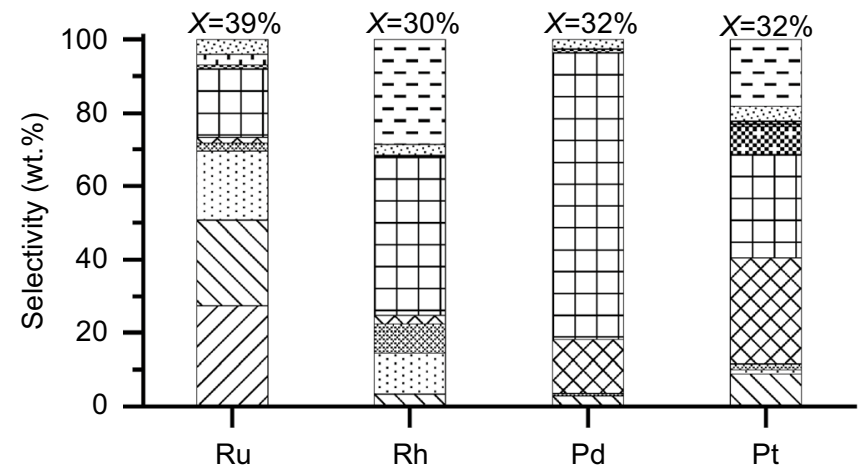

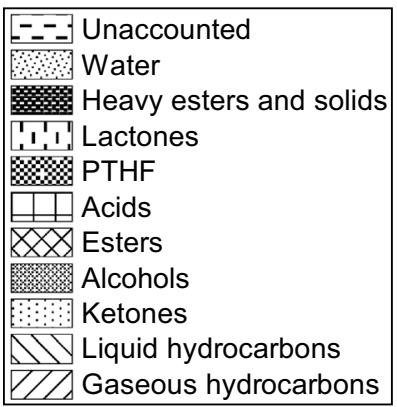

$\mathrm{Ru}$ produced less acids and esters than the other metals, but more ketones with nearly $20 \%$ selectivity.

The Rh catalyst (Fig. 3), compared to Ru, had a higher selectivity to acids (43\%) and alcohols (8\%). However, the amounts of produced ketones and hydrocarbons were lower than with $\mathrm{Ru}$. Despite all characterization efforts, approximately $30 \%$ of the expected product mass with the Rh catalyst remained unaccounted, which hinders the full assessment of the catalyst's performance.

With Pd, almost $80 \%$ of the products (Fig. 3) were acids. Pd also produced esters (15\%) and $<3 \%$ of liquid hydrocarbons. The product distribution of Pt was similar to Pd; however, it provided less acids (28\%), and more esters (29\%). With Pt, the selectivity to 2-pentyl tetrahydrofuran (PTHF) was high compared to other metals $(8 \%)$, and it provided the second highest selectivity towards liquid hydrocarbons (9\%). With both Pd and Pt, almost no ketones were produced. About $20 \%$ of the Pt products remained unaccounted.

Within each liquid product category, the products varied from each other by their carbon count $\left(\mathrm{C}_{4}-\mathrm{C}_{9}\right)$. The share of $n$-octane, the most abundant hydrocarbon, in the total liquid hydrocarbons was $64 \%$ with $\mathrm{Ru}, 79 \%$ with $\mathrm{Rh}, 96 \%$ with $\mathrm{Pd}$, and $81 \%$ with Pt. Hydrocarbons in the range of $\mathrm{C}_{4}-\mathrm{C}_{7}$ were obtained with $\mathrm{Ru}$ and $\mathrm{Rh}$, whilst $\mathrm{Pt}$ produced also $n$-nonane ( $16 \%$ of liquid hydrocarbons). The selectivity among the alcohols was almost exclusive to 3-octanol with $\mathrm{Ru}$ and $\mathrm{Rh}$, to nonanols with $\mathrm{Pd}$, and roughly equal to octanols and nonanols with Pt. Furthermore, nonanols varied according to the position of the hydroxyl group, i.e. carbons 1 or 4 , which correspond to the carboxyl and gamma carbons of the parent lactone, respectively. Especially with $\mathrm{Pt}$ and $\mathrm{Pd}$, also 1,4-nonanediol was obtained (Online Resource Figures S7, S11, S12 and Table S3). The four metals provided nonanoic acid as the most abundant acid and methane as the most abundant gas. In all cases except Rh, the most abundant esters were nonyl nonanoates (Online Resource Figure S9, S10 and Table S2), whereas Rh provided chiefly nonanoates of lower alcohols. The only detected aldehyde was nonanal, but the amount was low in all cases. Finally, Ru and $\mathrm{Rh}$ provided 3-octanone as the main ketone whilst $\mathrm{Pt}$ promoted 4-nonanone almost exclusively and Pd provided both ketones in similar amounts.

LC-MS analysis of the samples with $30-40 \%$ GNL conversions revealed the existence of a diester compound, 4-nonanoyloxynonyl nonanoate $\left(\mathrm{C}_{27} \mathrm{H}_{52} \mathrm{O}_{4}\right)$. The identification of the compound was accurate $(-0.46 \mathrm{ppm}$ difference from the target mass). The diester formed with $\mathrm{Pt}$ and $\mathrm{Pd}$ catalysts, but not with $\mathrm{Ru}$. The $\mathrm{Rh}$ catalyst produced possibly only a trace of the diester; the corresponding chromatographic peak was minuscule. To our knowledge, the equivalent diester in GVL HDO has not been reported in the literature. The mass spectrum of the diester and the LC-MS chromatograms are presented in the Online Resource (Figures S13, S14 and Table S4).

The development of the products throughout the reaction is depicted in Fig. 4 as product molar yields as a function of GNL conversion. The least abundant product groups are not shown. With all the metals, the acids (primarily nonanoic acid) built up as the reactions progressed. In the cases of $\mathrm{Rh}$ and $\mathrm{Pd}$, the acids vastly outweighed all other products. Although the acid yield levels varied widely from catalyst to catalyst, they were the only product group that followed a similar pattern as a function of conversion with all four catalysts. In general, most of the products accumulated with increasing conversion in the presence of all catalysts, whilst the alcohols decayed in all cases. Exceptionally, PTHF decayed with Rh (not shown), but accumulated with Pd and Pt. With Ru, PTHF (not shown) decayed from the second to the third data point and increased afterwards.

What is stated above about the variations within the product groups at $280{ }^{\circ} \mathrm{C}$ applies throughout the conversion levels with some exceptions. At the lowest conversion with $\mathrm{Ru}$, carbon monoxide, not methane, comprised the gas phase almost entirely. The proportions of these gases interchanged afterwards. The proportions of the gas contents also shifted with $\mathrm{Pd}$ and $\mathrm{Pt}$, which evolved a greater share of $\mathrm{C}_{2}$ to $\mathrm{C}_{4}$ hydrocarbons at the two lower conversions, but more methane afterwards. On the other hand, Ru provided a greater amount and variety of lower esters and lower acids with increasing conversion. Finally, lower alcohols, rather than 
Fig. 4 Molar yields of grouped products as a function of GNL conversion on $\mathbf{a ~} \mathrm{Ru} / \mathrm{ZrO}_{2}, \mathbf{b} \mathrm{Rh} /$ $\mathrm{ZrO}_{2}, \mathbf{c} \mathrm{Pd} / \mathrm{ZrO}_{2}, \mathbf{d} \mathrm{Pt} / \mathrm{ZrO}_{2}$. Note the different scales in the figures. Note that the Ru catalyst contained chloride species
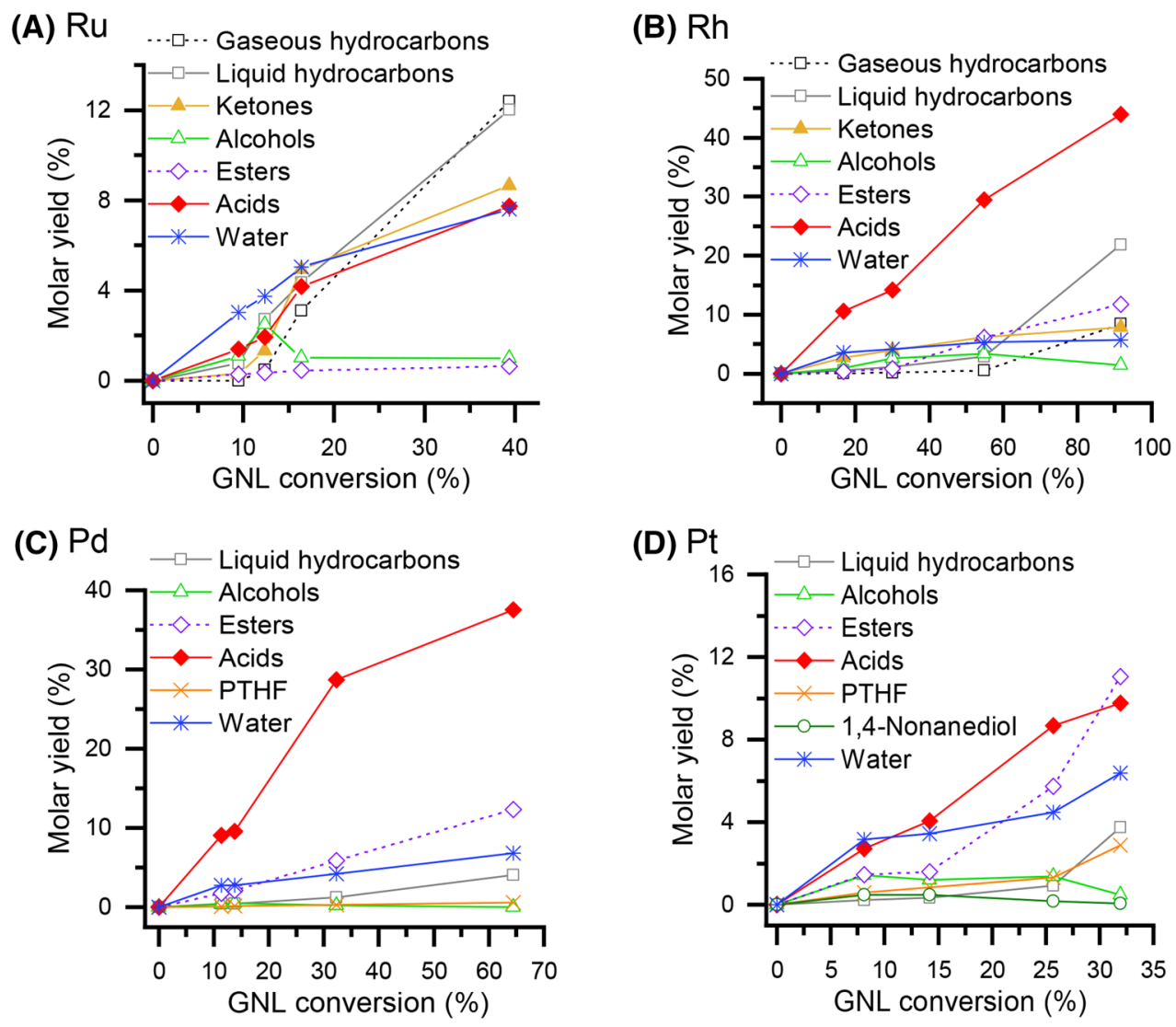

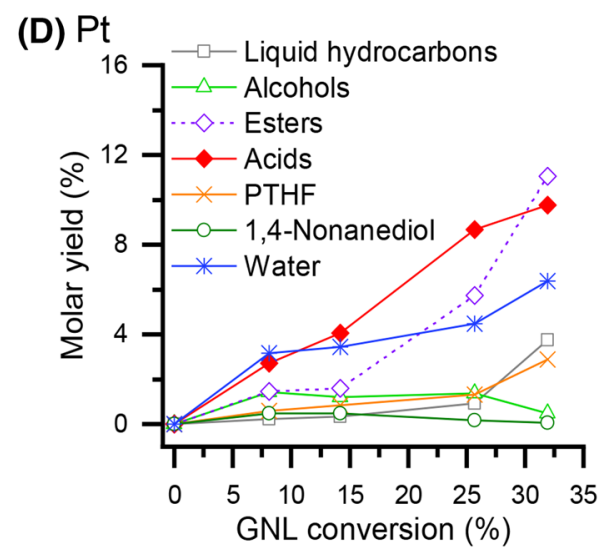

octanols and nonanols, were obtained at the lowest conversion with $\mathrm{Ru}$ and at the two lowest conversions with $\mathrm{Pd}$, and Pt.

After most of the experiments at $280{ }^{\circ} \mathrm{C}$, all the produced water was in the organic phase. Only $\mathrm{Ru}$ provided a separate aqueous phase at $39 \%$ conversion and $\mathrm{Rh}$ at $91 \%$ conversion. In the first case, the water presented a $\mathrm{pH}$ of 2 and $\geq 3000 \mathrm{mg} / \mathrm{L}$ chlorides (from the catalyst precursor, see Sect. 4). Traces of GNL, $\gamma$-heptalactone, and acetic, propanoic, butanoic, and pentanoic acids were found in the formed water phase. The aqueous phase obtained with $\mathrm{Rh}$ had a $\mathrm{pH}$ of 5 and it contained traces of GNL and $\mathrm{C}_{2}$ to $\mathrm{C}_{7}$ acids.

\subsection{Temperature Effect on the Performance of Ru Catalyst}

Because of Ru's high selectivity towards the desired hydrocarbons at $280{ }^{\circ} \mathrm{C}$, the $\mathrm{Ru}$ catalyst was studied further. The effect of reaction temperature on the performance of the $\mathrm{Ru}$ catalyst was examined at 220 and $250{ }^{\circ} \mathrm{C}$ for $300 \mathrm{~min}$. Higher temperatures were thought to be less beneficial for LA dimers due to thermal reactions. Thus, the GNL experiments were conducted below $300{ }^{\circ} \mathrm{C}$.

The lowest GNL conversion of $25 \%$ was achieved at the lowest tested temperature $\left(220{ }^{\circ} \mathrm{C}\right)$. At $250{ }^{\circ} \mathrm{C}$, the conversion increased to $37 \%$ and at $280{ }^{\circ} \mathrm{C}$, to $39 \%$. The $\mathrm{H}_{2}$ conversion (Online Resource) was $40 \%$ at $220{ }^{\circ} \mathrm{C}, 60 \%$ at $250{ }^{\circ} \mathrm{C}$, and $80 \%$ at $280{ }^{\circ} \mathrm{C}$. Compared to the $\mathrm{O} / \mathrm{C}$ ratio of GNL, some deoxygenation was observed with $\mathrm{Ru}$ at all the tested temperatures (Fig. 2). The O/C ratio decreased slightly with increasing temperature. On the other hand, the hydrogen content of the reaction products was considerably higher than GNL's. The H/C ratio was very similar at 220 and $250{ }^{\circ} \mathrm{C}$, but slightly lower at $280{ }^{\circ} \mathrm{C}$.

The product distributions obtained with the $\mathrm{Ru}$ catalyst at different reaction temperatures are presented in Fig. 5. By increasing the reaction temperature, the selectivity to alcohols and PTHF decreased. By contrast, more gaseous and liquid hydrocarbons, ketones, acids, and lactones with shorter $\left(<\mathrm{C}_{5}\right)$ side chains formed at higher temperatures. The amount of esters were low in all the tested temperatures and low compared to the other metals at $280{ }^{\circ} \mathrm{C}$ (Fig. 3). The lower the reaction temperature, the higher the share of products which remained unknown despite all the efforts in product analysis.

The product chain lengths hardly varied at the tested temperatures. The most abundant hydrocarbon in all cases was octane, the second was heptane, and the third, nonane. More branched hydrocarbons formed at higher temperatures, but still in low amounts. Ketones were mainly 3-octanone and 4-nonanone at all temperatures, and aldehydes were not produced at all. The main alcohols were 3-octanol, 4-nonanol, 
Fig. 5 Grouped product selectivities obtained with $\mathrm{Ru} /$ $\mathrm{ZrO}_{2}$ catalyst. GNL conversion $(X)$ is marked on top of the bars. Reaction conditions: $0.6 \mathrm{~g}$ catalyst, $\sim 3 \%$ metal loading, $23 \mathrm{~mL}$ GNL (pure), 57.5 bar $\mathrm{H}_{2}$, 300 min. Reaction temperature in ${ }^{\circ} \mathrm{C}$ is in parenthesis next to labels. Note that the Ru catalyst contained chloride species

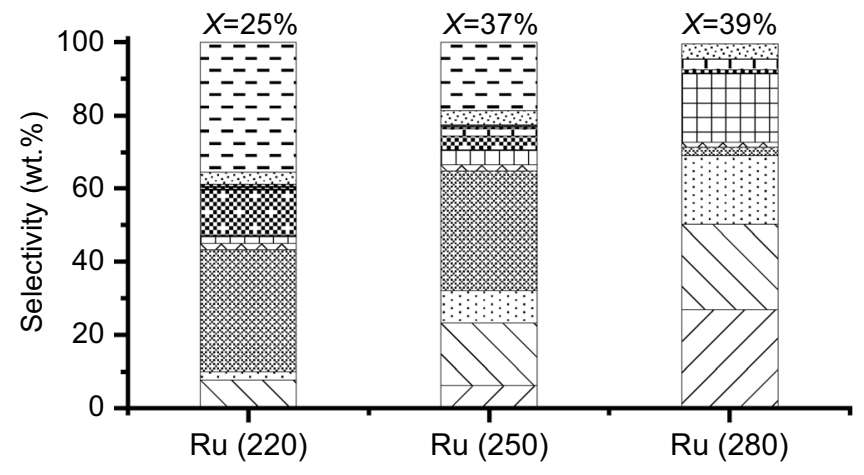

and ethanol. The selectivity to 1,4-nonanediol was inversely proportional to reaction temperature. The main acid was nonanoic acid and nonyl nonanoate was the most abundant among the identified esters. An independent aqueous phase with a pH of 4 formed at $250{ }^{\circ} \mathrm{C}$. The aqueous phase contained traces of GNL and lower lactones, nonanoic acid, alcohols and ketones. The aqueous phase that formed at $280{ }^{\circ} \mathrm{C}$ is reported in the previous section.

\subsection{Characterization of Spent Catalysts}

Spent catalysts (washed with ethanol and dried at $100{ }^{\circ} \mathrm{C}$ ) were characterized with physisorption, chemisorption, and STEM, after use in experiments $\left(280{ }^{\circ} \mathrm{C}, 57.5 \mathrm{bar} \mathrm{H}_{2}\right)$ with $30-40 \%$ conversion. The metal contents in the spent catalysts were not measured, and for calculations based on chemisorption measurements, the metal loadings of the fresh catalysts were used. STEM images were taken from the spent samples after chemisorption (Figure S3). The BET surface areas decreased during reaction by about $10 \%$ on average, except for Pt. The metal dispersions decreased by $40-80 \%$ and the pore volumes, by 4-40\%, except for Ru, for which both metal dispersion and pore volume increased by $72 \%$ and $27 \%$, respectively. From the STEM images, the metal particle sizes increased by $20-140 \%$. The used, unwashed catalysts were analyzed by TGA in order to estimate the amount of carbonaceous solids deposited during the experiments. After drying in inert gas up to $250{ }^{\circ} \mathrm{C}$, about $2 \% \pm 0.2 \%$ of the used catalysts' mass was combustible below $900{ }^{\circ} \mathrm{C}$. Only in the case of the experiment with $\mathrm{Ru}$ at $220^{\circ} \mathrm{C}$, the combustible mass was $3.9 \%$ of the used catalyst. A typical TGA thermogram is presented in Figure S4.

\section{Discussion}

\subsection{Characterization of Fresh Catalysts}

Excepting Ru, the fresh catalysts had a good dispersion compared to values reported in the literature [20, 21, 30]. For Ru and Pd, the metal particle sizes obtained by chemisorption were larger than the sizes observed by STEM. By resorting to a third technique, XRD, the metal particles appeared to be small and well dispersed, as no metal peaks were detected. The disagreement of STEM with chemisorption might have resulted from the deposited particles not being thoroughly in the metallic form. In the case of Ru, the catalyst likely remained partially chlorinated after calcination and reduction, as evidenced by the chlorides detected in the aqueous phases of some HDO products (chlorides were washable from the reactor and they were inactive in the organic phase, as shown by the blank experiments). The $\mathrm{RuCl}_{3}$ precursor was the only source of chlorides in the overall workflow. Chlorides might have occluded chemisorption sites [31, 32]; therefore, the chemisorption results may represent the initially available catalytic active sites, whereas the STEM results may provide more accurate measurements of the particle sizes.

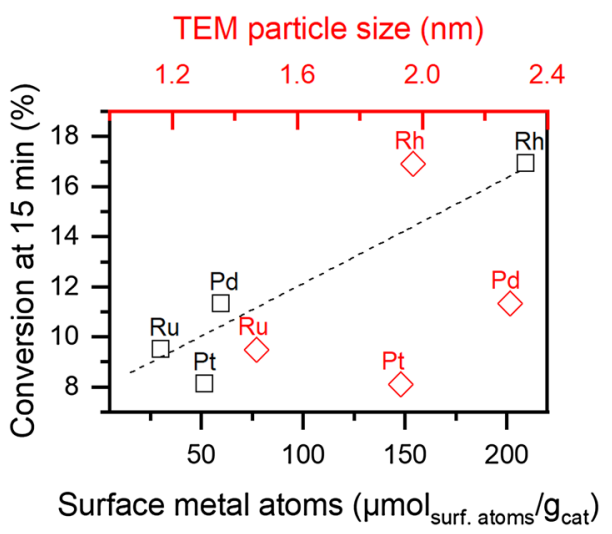

Fig. 6 Conversion of GNL on $\mathrm{ZrO}_{2}$-supported catalysts at short reaction times $(15 \mathrm{~min})$ as a function of the amount of surface metal atoms from chemisorption (square) and average metal particle size measured by STEM (diamond). Reaction conditions: $0.6 \mathrm{~g}$ catalyst, $\sim 3 \%$ metal loading, $23 \mathrm{~mL}$ GNL (pure), $280{ }^{\circ} \mathrm{C}, 57.5$ bar $\mathrm{H}_{2}$ 


\subsection{Activity and Selectivity}

There was no obvious dependence of activity on the catalysts' particle sizes (Fig. 6). However, when plotted against the amount of surface metal atoms (from chemisorption), a correlation with conversion emerges. Hence, it appears that the differences in activity between the catalysts result from the different amounts of surface atoms, due to the different atomic masses of the elements. Ru, having the lowest atomic mass, was expected to present the greatest amount of surface atoms. However, its actual position in the graph likely resulted from the initial occupation of active sites by residual $\mathrm{Cl}$ species, which occluded chemisorption sites $[31,33]$. Nevertheless, taking the initial TOFs as a gage of the activity per surface active site, it appears that Ru's sites were the most active $\left(1 \mathrm{~s}^{-1}\right)$ and Rh's sites were the least active $\left(0.2 \mathrm{~s}^{-1}\right)$.

Although an exponential dependence of conversion on temperature was expected, similar conversions were attained at 250 and $280^{\circ} \mathrm{C}$ with Ru (Fig. 5). Apart from the experimental error, this similarity might result from a highly competitive adsorption of the various reaction products against GNL. On the other hand, internal mass transfer limitations could cause the similarity. External mass transfer limitations were estimated to be negligible by the Carberry criterion (see Online Resource). $\mathrm{H}_{2}$ conversions had a more pronounced dependence on reaction temperature, possibly because $\mathrm{H}_{2}$ and oxygenate reactants were activated on different site types [34, 35].

The H/C ratios found by elemental analysis of several HDO product mixtures, i.e. 1.9-2.3 (Fig. 2), roughly agreed with the values calculated as weighted averages of the identified products, i.e. 2.0-2.2 (Figs. 3, 5). The variations likely arise from an imperfect product characterization. Hydrogen uptake can occur both by HDO and by cracking. Thus, the H/C of GNL (1.78) can increase up to 2.22 by full deoxygenation to nonane and to higher values by further cracking. With the $\mathrm{Ru}$ experiments at different temperatures, the $\mathrm{H} / \mathrm{C}$ obtained at $280{ }^{\circ} \mathrm{C}$ was slightly lower than at 220 and $250{ }^{\circ} \mathrm{C}$. This agrees with the calculated ratios: 2.2 for the lower temperatures and 2.1 for $280{ }^{\circ} \mathrm{C}$. The low temperature products were rich in alcohols and hydrocarbons with $\mathrm{H} / \mathrm{C}>2.2$, whilst the $280{ }^{\circ} \mathrm{C}$ had a high contents of nonanoic acid and ketones with $\mathrm{H} / \mathrm{C}=2$.

Most of the hydrogen was spent in methanation of $\mathrm{CO}$ on the Ru catalyst; a high amount of $\mathrm{H}_{2}$ was consumed, which was reflected in the amount of $\mathrm{CH}_{4}$. The composition of the gas phase with $\mathrm{Ru}$ shifted from mainly $\mathrm{CO}$ at lower conversion to mainly $\mathrm{CH}_{4}$ at higher conversion. According to Chen et al. [30], partially oxidized Ru (oxidation caused by surface hydroxyls on $\mathrm{ZrO}_{2}$ ) allows for strong, thermally stable $\mathrm{CO}$ adsorption. This in turn might facilitate methanation.
Thus, the amount of $\mathrm{CH}_{4}$ obtained with $\mathrm{Ru} / \mathrm{ZrO}_{2}$ was much higher than with the other catalysts possibly due to a decarbonylation and methanation mechanism, as Ru metal favors decarbonylation $[30,36,37]$. The presence of residual $\mathrm{Cl}$ species has not been identified to interact with adsorbed $\mathrm{CO}$ species or affect their reactivity $[31,33]$. The amount of methane also increased with temperature, which is explained by Arrhenius's law, as the thermodynamics were not limiting the methanation reactions at our reaction conditions (calculated via HSC Chemistry 6 software, using reactions described by Gao et al. [38]). Similarly, short-chained liquid products, formed by cracking of the GNL side-chain and of $\mathrm{C}_{8}$ and $\mathrm{C}_{9}$ products, increased with temperature.

Pd produced mainly nonanoic acid and esters. Pd was capable of opening the lactone ring, but its HDO activity was low. The inactivity of Pd in the hydrogenation of carboxylic acids has been reported in the literature [39]. Alcohols were formed on Pd and were directly consumed in esterification; thus, the yield of hydrocarbons was low (see Sect. 4.4).

Nearly $50 \%$ of the products with Pt were acids and esters, which agrees with previous literature [13, 40, 41]. Two GNL molecules are needed to form nonyl nonanoate, which leads to the removal of oxygen as water. Oxygen is also rejected in $\mathrm{PTHF}$ formation. Hence, the low $\mathrm{O} / \mathrm{C}$ ratio of the $\mathrm{Pt}$ product with respect to GNL in the van Krevelen diagram (Fig. 2) is explained, in spite of the predominant content of oxygenates in this product (Fig. 3).

\subsection{Characterization of Spent Catalysts}

The metal dispersion changed during the experiments. The increase in Ru dispersion might be explained by the reduction of ruthenium chloride producing metallic sites and $\mathrm{HCl}$ during the experiment. With the other metals, the dispersion decreased. This was caused by particle agglomeration during the reaction, which was evidenced by the particle sizes measured from the STEM images (Table 1); the particles were larger on the spent catalysts than on the fresh ones. On the other hand, carbonaceous solids deposited on the catalysts perhaps partially covered the metals. This notion was supported by the fact that chemisorption provided greater particle size values than STEM for the spent catalysts. Chemisorption particle sizes were exaggerated because less chemisorption sites were available due to coverage with solid deposits. Less chemisorption sites translated into a lower calculated metal dispersion. Furthermore, in TGA of used catalysts (Online Resource Figure S4), the greater mass loss $(\sim 1.5 \%)$, from 200 to $300{ }^{\circ} \mathrm{C}$, corresponds to coke oxidation on the metal [42], whereas the lesser mass loss $(\sim 0.5 \%)$, starting at $500{ }^{\circ} \mathrm{C}$, corresponds to coke oxidation on the support. Hence, about $3 / 4$ of the quantified solid deposits were perhaps located on the metal. 
Fig. 7 Summary of the GNL HDO products on noble metals supported on $\mathrm{ZrO}_{2}$

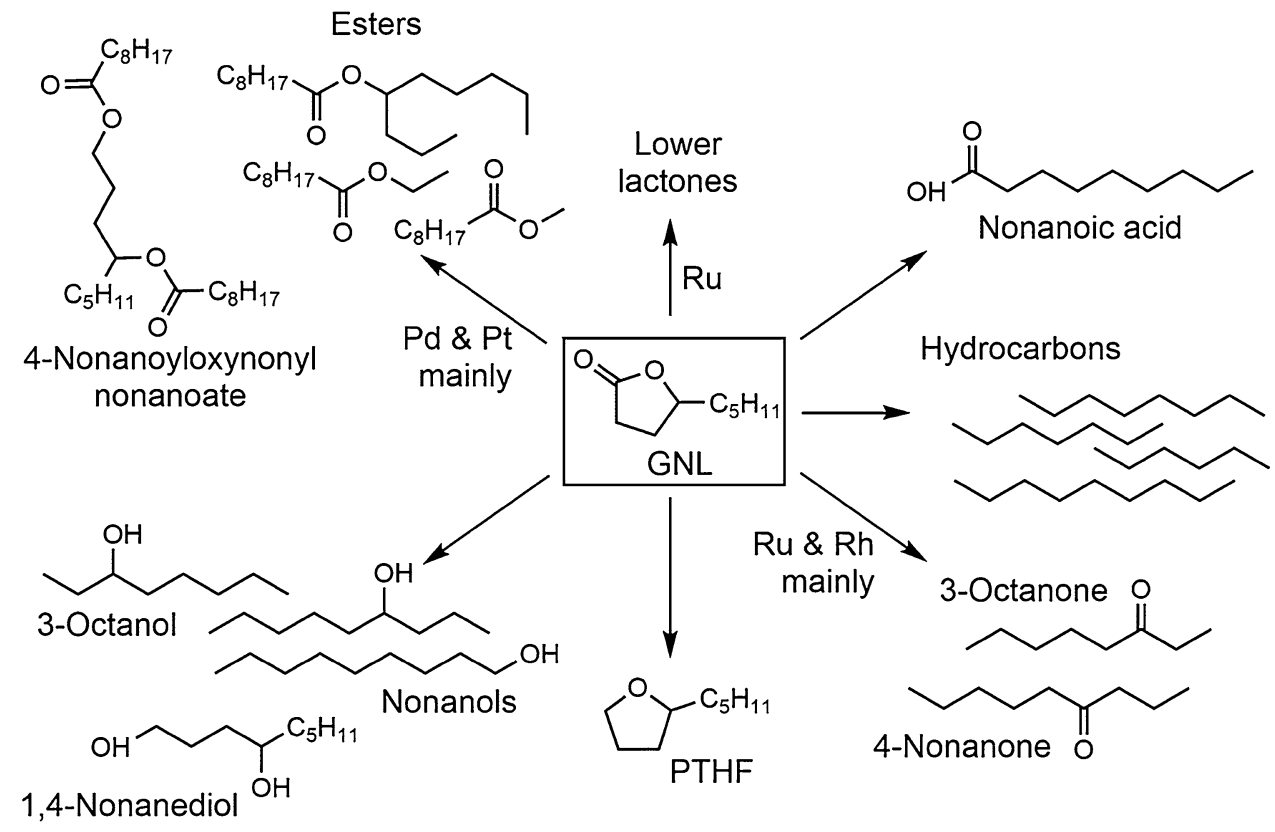

\subsection{HDO Products}

The summary of the products obtained from GNL HDO with noble metals is illustrated in Fig. 7. Secondary alcohols can form directly from GNL by decarbonylation or deoxygenation of a ring-opening surface intermediate [36]. The decarbonylation route is energetically favored on $\mathrm{Ru}$ $[36,37]$. This might explain the low yields of nonanoic acid provided by $\mathrm{Ru}$ as compared to the other metals. From the yield profiles (Fig. 4), it is evident that the alcohols acted as intermediates, producing hydrocarbons. The production of liquid hydrocarbons and water on $\mathrm{Ru}$ at $280{ }^{\circ} \mathrm{C}$ was higher than at lower temperatures. Furthermore, the amount of alcohols was lower at higher temperatures (Fig. 3). Hence, the higher temperature could promote the HDO of alcohols through Arrhenius's law, as the thermodynamic equilibrium was not restricting in the used conditions (calculated via HSC Chemistry 6 software using 3-octanol as a model compound). However, the formation of alcohols is a consequence of several reactions (e.g. ring-opening and HDO), and there might also be changes in the rates of these reactions as well as competitive adsorption to result into lower amount of alcohols at higher temperature. The amount of PTHF was inversely proportional to temperature. Analogously, the MTHF conversion in $\mathrm{HDO}$ on $\mathrm{Ru} / \mathrm{C}$ has been reported to increase exponentially with respect to temperature, as expected from kinetics [43]. Furthermore, in the GVL literature with $\mathrm{Ru} / \mathrm{C}$, the temperature is kept low $\left(190{ }^{\circ} \mathrm{C}\right)$ when high yields of 2-butanol [36] and MTHF [44] are desired.

The lactone ring can open without oxygen removal resulting in 1,4-nonanediol. The low concentrations of 1,4-nonanediol suggested that it was also an intermediate, as reported elsewhere [36, 37, 44]. PTHF formed from 1,4-nonanediol $[36,37,44]$ and reacted further on $\mathrm{Ru} /$ $\mathrm{ZrO}_{2}$ and $\mathrm{Rh} / \mathrm{ZrO}_{2}$, as attested by its low concentration and the decrease in the latter part of its yield profile on these two metals. A HDO study of MTHF reports its conversion to 2-pentanone and 1-pentanol as primary products [45]. With $\mathrm{Ru}$, the amount of PTHF was high at lower temperatures and low at $280{ }^{\circ} \mathrm{C}$ (Fig. 3), whereas the amount of ketones was low at the lower temperatures and high at $280{ }^{\circ} \mathrm{C}$. These shifts support the notion that ketones possibly formed from PTHF. Formation of secondary alcohols from 1,4-pentanediol [44] has also been observed on $\mathrm{Ru} / \mathrm{C}$. 1,4-Nonanediol reacted also with two nonanoic acid molecules to form the diester, 4-nonanoyloxynonyl nonanoate. The diester was observed only with Pt and Pd, which produced more reactants for this reaction.

In the case of Rh and Pd, relatively high shares of the products remained unaccounted (Fig. 3). In the case of Pd, it can be partly explained with the diester, which was not added to the selectivity calculations. No other nonvolatile compounds were detected either by LC-MS or GC with silylated samples.

Nonanoic acid formed and accumulated, especially on $\mathrm{Rh}$ and $\mathrm{Pd}$. The analogous conversion of GVL to valeric acid has been studied on bifunctional catalysts [13, 40, 41]. With $\mathrm{Al}_{2} \mathrm{O}_{3}$-containing support, the acid forms in two steps. Firstly, the lactone ring opens on the catalyst's acid sites and secondly, the resulting alkenoic acid is hydrogenated on the catalyst's metal sites. The second step is thermodynamically favorable and irreversible [46]. No alkenoic acids were observed in the present work, suggesting that the ring-opening mechanism might have been different on less 
acidic $\mathrm{ZrO}_{2}$ or that the hydrogenation of the alkenoic acid proceeded very rapidly at 57.5 bar $_{2}$. Although nonanoic acid esterified, mainly on $\mathrm{Pt} / \mathrm{ZrO}_{2}$, its net production never declined, indicating a high rate of formation. Nonanoic acid might also be converted to $n$-octane. The decarbonylation of propanoic acid to ethane on $\mathrm{Ru} / \mathrm{ZrO}_{2}$ has been shown to proceed through an acyl surface intermediate, which in turn forms by hydrogenation-dehydration of a surface carboxylate [30]. Carboxylic acids are especially undesirable in fuel due to their corrosiveness [47].

Ketones formed abundantly and accumulated in the product mixtures (Fig. 4), especially over $\mathrm{Ru} / \mathrm{ZrO}_{2}$. Although ketones can be hydrogenated to their corresponding alcohol, a kinetic HDO study in the literature showed that the rate of ketone formation is three orders of magnitude greater than the rate of its consumption [45]. Studies made with noble metals [48, 49] indicated that $\mathrm{Pd}$ and Pt were active in converting ketone to their corresponding hydrocarbon, but $\mathrm{Rh}$ and $\mathrm{Ru}$ were not active in hydrogenating the ketone group. Ketones are inadequate for fuel blends due to their ability to degrade plastics and rubber, and due to their possible instability [47].

\section{Conclusions}

The HDO of GNL was studied in order to assess the potential of LA dimers as intermediates to lignocellulose-based biofuels. Hydrocarbons $\left(\mathrm{C}_{8}-\mathrm{C}_{9}\right)$ were produced from GNL in $\mathrm{HDO}$ catalyzed by noble metals on $\mathrm{ZrO}_{2}$ at $280{ }^{\circ} \mathrm{C}$. The highest selectivity to hydrocarbons was achieved with $\mathrm{Ru}$ (nearly $24 \%$ ). $\mathrm{Rh}$ performed similarly to $\mathrm{Ru}$, but it provided higher conversion, it was less selective to hydrocarbons, and more selective to acids. Pd was mostly selective to acids, while Pt provided high yields of esters. The activity of the catalysts in terms of GNL conversion correlated with the amount of surface metal atoms. Thus, the observed differences in activity among the catalysts are likely attributable to different amounts of active sites.

$\mathrm{Ru}$ was tested at lower reaction temperatures (220 and $250{ }^{\circ} \mathrm{C}$ ). The lower temperatures resulted in more reaction intermediates, such as alcohols and PTHF, but less ketones and hydrocarbons.

The HDO of GNL with noble metal catalysts below $300{ }^{\circ} \mathrm{C}$ proceeded through numerous oxygenated intermediates. $\mathrm{Ru}$ and $\mathrm{Rh}$ provided the largest yields of liquid hydrocarbons at the highest conversions attained, but also methanation was observed. These results can inform future research on HDO of LA dimers with noble metal catalysts for the production of biofuel components.
Acknowledgements Open access funding provided by Aalto University. The authors thank Heidi Meriö-Talvio for analytical help, Tyko Viertiö for performing physi- and chemisorption measurements and Johanna Helminen from Neste Corporation for performing XRF measurements. For the acquisition of STEM images, we acknowledge the provision of facilities and technical support by Dr. Hua Jiang from Aalto University at OtaNano - Nanomicroscopy Center (Aalto-NMC). Aalto University's Bioeconomy infrastructure and Raw materials research infrastructure are also acknowledged for equipment support.

Funding Funding for this work was provided by Neste Corporation. Author E. Mäkelä acknowledges a grant from Aalto University.

\section{Compliance with Ethical Standards}

Conflict of interest All authors declared that they have no conflict of interests.

Open Access This article is distributed under the terms of the Creative Commons Attribution 4.0 International License (http://creativeco mmons.org/licenses/by/4.0/), which permits unrestricted use, distribution, and reproduction in any medium, provided you give appropriate credit to the original author(s) and the source, provide a link to the Creative Commons license, and indicate if changes were made.

\section{References}

1. Chen M, Smith PM (2017) The U.S. cellulosic biofuels industry: expert views on commercialization drivers and barriers. Biomass Bioenerg 102:52-61. https://doi.org/10.1016/j.biomb ioe.2017.05.002

2. Nanda S, Dalai AK, Kozinski JA (2014) Butanol and ethanol production from lignocellulosic feedstock: biomass pretreatment and bioconversion. Energy Sci Eng 2:138-148. https://doi. org/10.1002/ese 3.41

3. Chheda JN, Huber GW, Dumesic JA (2007) Liquid-phase catalytic processing of biomass-derived oxygenated hydrocarbons to fuels and chemicals. Angew Chem 46:7164-7183. https://doi. org/10.1002/anie.200604274

4. Werpy T, Petersen G (2004) Top value added chemicals from biomass volume I-results of screening for potential candidates from sugars and synthesis gas. USA. https://doi.org/10.2172/15008859, https://www.osti.gov/servlets/purl/15008859. Accessed $14 \mathrm{Feb}$ 2019

5. Climent MJ, Corma A, Iborra S (2014) Conversion of biomass platform molecules into fuel additives and liquid hydrocarbon fuels. Green Chem 16:516. https://doi.org/10.1039/c3gc41492b

6. Yan K, Wu G, Lafleur T, Jarvis C (2014) Production, properties and catalytic hydrogenation of furfural to fuel additives and valueadded chemicals. Renew Sustain Energy Rev 38:663-676. https:// doi.org/10.1016/j.rser.2014.07.003

7. Yan K, Jarvis C, Gu J, Yan Y (2015) Production and catalytic transformation of levulinic acid: a platform for speciality chemicals and fuels. Renew Sustain Energy Rev 51:986-997. https:// doi.org/10.1016/j.rser.2015.07.021

8. Yan K, Yang Y, Chai J, Lu Y (2015) Catalytic reactions of gammavalerolactone: a platform to fuels and value-added chemicals. Appl Catal B Environ 179:292-304. https://doi.org/10.1016/j. apcatb.2015.04.030

9. Bozell JJ, Moens L, Elliott DC et al (2000) Production of levulinic acid and use as a platform chemical for derived products. Resour 
Conserv Recycl 28:227-239. https://doi.org/10.1016/S0921 -3449(99)00047-6

10. Bond JQ, Upadhye AA, Olcay H et al (2014) Production of renewable jet fuel range alkanes and commodity chemicals from integrated catalytic processing of biomass. Energy Environ Sci 7:1500-1523. https://doi.org/10.1039/C3EE43846E

11. Bond JQ, Wang D, Alonso DM, Dumesic JA (2011) Interconversion between $\gamma$-valerolactone and pentenoic acid combined with decarboxylation to form butene over silica/alumina. J Catal 281:290-299. https://doi.org/10.1016/j.jcat.2011.05.011

12. Bond JQ, Alonso DM, Wang D et al (2010) Integrated catalytic conversion of $\gamma$-Valerolactone to liquid alkanes for transportation fuels. Science 327:1110-1114. https://doi.org/10.1126/scien ce. 1184362

13. van den Brink PJ, von Hebel KL, Lange J-P, Petrus L (2006) A process for the hydrogenation of a lactone or of a carboxylic acid or an ester having a gamma-carbonyl group. WO 2006/067171 A1. https://worldwide.espacenet.com/publicationDetails/ originalDocument?FT $=\mathrm{D} \&$ date $=20060629 \& \mathrm{DB}=\&$ local $\mathrm{e}=\& \mathrm{CC}=\mathrm{WO} \& \mathrm{NR}=2006067171 \mathrm{~A} 1 \& \mathrm{KC}=\mathrm{A} 1 \& \mathrm{ND}=3 \#$. Accessed 28 Sept 2018

14. Pham HN, Pagan-Torres YJ, Serrano-Ruiz JC et al (2011) Improved hydrothermal stability of niobia-supported Pd catalysts. Appl Catal A Gen 397:153-162. https://doi.org/10.1016/j.apcat a.2011.02.026

15. Serrano-Ruiz JC, Braden DJ, West RM, Dumesic JA (2010) Conversion of cellulose to hydrocarbon fuels by progressive removal of oxygen. Appl Catal B Environ 100:184-189. https://doi. org/10.1016/j.apcatb.2010.07.029

16. Huber GW, Chheda JN, Barrett CJ, Dumesic JA (2005) Production of liquid alkanes by aqueous-phase processing of biomass-derived carbohydrates. Science 308:1446-1450. https://doi.org/10.1126/ science. 1111166

17. Blessing RW, Petrus L (2006) A process for the dimerization of levulinic acid, dimers obtainable by such process and esters of such dimers. WO 2006/056591 A1. https://worldwide.espacenet. $\mathrm{com} /$ publicationDetails/originalDocument?FT $=$ D\&date $=20060$ $601 \& \mathrm{DB}=\& 1$ oc al e $=\& \mathrm{CC}=\mathrm{WO} \& \mathrm{NR}=2006056591$ $\mathrm{A} 1 \& \mathrm{KC}=\mathrm{A} 1 \& \mathrm{ND}=3 \#$. Accessed 28 Sept 2018

18. Käldström M, Lindblad M, Lamminpää K et al (2017) Carbon chain length increase reactions of platform molecules derived from $\mathrm{C5}$ and C6 sugars. Ind Eng Chem Res 56:13356-13366. https://doi. org/10.1021/acs.iecr.7b01904

19. Mohammad M, Kandaramath Hari T, Yaakob Z et al (2013) Overview on the production of paraffin based-biofuels via catalytic hydrodeoxygenation. Renew Sustain Energy Rev 22:121-132. https ://doi.org/10.1016/j.rser.2013.01.026

20. Bie Y, Gutierrez A, Viljava TR et al (2013) Hydrodeoxygenation of methyl heptanoate over noble metal catalysts: catalyst screening and reaction network. Ind Eng Chem Res 52:11544-11551. https:// doi.org/10.1021/ie4012485

21. Gutierrez A, Kaila RK, Honkela ML et al (2009) Hydrodeoxygenation of guaiacol on noble metal catalysts. Catal Today 147:239-246. https://doi.org/10.1016/j.cattod.2008.10.037

22. Brunauer S, Emmett PH, Teller E (1938) Adsorption of gases in multimolecular layers. J Am Chem Soc 60:309-319. https://doi. org/10.1021/ja01269a023

23. Barrett EP, Joyner LG, Halenda PP (1951) The determination of pore volume and area distributions in porous substances. I. Computations from nitrogen isotherms. J Am Chem Soc 73:373-380. https ://doi.org/10.1021/ja01145a126

24. Shen X, Garces L, Ding Y et al (2008) Behavior of H2 chemisorption on $\mathrm{Ru} / \mathrm{TiO} 2$ surface and its application in evaluation of Ru particle sizes compared with TEM and XRD analyses. Appl Catal A Gen 335:187-195. https://doi.org/10.1016/j.apcata.2007.11.017
25. Bergeret G, Gallezot P (2008) Particle size and dispersion measurements. In: Ertl G, Knözinger H, Schuth F, Weitkamp J (eds) Handbook of heteregeneous catalysis, 2nd edn. WILEY-VHC, Weinheim, pp 738-746

26. Scanlon JT (1985) Calculation of flame ionization detector relative response factors using the effective carbon number concept. J Chromatogr Sci 23:333-340

27. van Krevelen DW (1950) Graphical-statistical method for the study of structure and reaction processes of coal. Fuel 29:269-283

28. Behrens M, Schlögl R (2012) X-Ray diffraction and small angle X-ray scattering. In: Che M, Védrine JC (eds) Characterization of solid materials and heterogeneous catalysts: from structure to surface reactivity, 1st edn. Wiley-VCH, Weinheim, pp 611-652

29. Leitner W, Klankermayer J, Pischinger S et al (2017) Advanced biofuels and beyond: chemistry solutions for propulsion and production. Angew Chem 56:5412-5452. https://doi.org/10.1002/anie.20160 7257

30. Chen L, Zhu Y, Zheng H et al (2012) Aqueous-phase hydrodeoxygenation of propanoic acid over the $\mathrm{Ru} / \mathrm{ZrO} 2$ and $\mathrm{Ru}-\mathrm{Mo} / \mathrm{ZrO} 2$ catalysts. Appl Catal A Gen 411-412:95-104. https://doi.org/10.1016/j. apcata.2011.10.026

31. Nawdali M, Bianchi D (2002) The impact of the Ru precursor on the adsorption of $\mathrm{CO}$ on $\mathrm{Ru} / \mathrm{Al} 2 \mathrm{O} 3$ : amount and reactivity of the adsorbed species. Appl Catal A Gen 231:45-54. https://doi. org/10.1016/S0926-860X(01)00922-X

32. Narita T, Miura H, Ohira M et al (1987) The effect of reduction temperature on the chemisorptive properties of $\mathrm{Ru} / \mathrm{Al} 2 \mathrm{O} 3$ : effect of chlorine. Appl Catal 32:185-190. https://doi.org/10.1016/S0166 -9834(00)80624-7

33. Mieth JA, Schwartz JA (1989) The effect of catalyst preparation on the performance of alumina-supported ruthenium catalysts. 2 . The impact of residual chloride. J Catal 118:218-226. https://doi. org/10.1016/0021-9517(89)90312-6

34. Foraita S, Fulton JL, Chase ZA et al (2015) Impact of the oxygen defects and the hydrogen concentration on the surface of tetragonal and monoclinic $\mathrm{ZrO} 2$ on the reduction rates of stearic acid on $\mathrm{Ni} / \mathrm{ZrO} 2$. Chemistry 21:2423-2434. https://doi.org/10.1002/ chem. 201405312

35. Bie Y, Lehtonen J, Kanervo J (2016) Hydrodeoxygenation (HDO) of methyl palmitate over bifunctional $\mathrm{Rh} / \mathrm{ZrO} 2$ catalyst: insights into reaction mechanism via kinetic modeling. Appl Catal A Gen 526:183-190. https://doi.org/10.1016/j.apcata.2016.08.030

36. Rozenblit A, Avoian AJ, Tan Q et al (2016) Reaction mechanism of aqueous-phase conversion of $\gamma$-valerolactone (GVL) over a Ru/C catalyst. J Energy Chem 25:1008-1014. https://doi.org/10.1016/j. jechem.2016.11.010

37. Bababrik RM, Wang B, Resasco DE (2017) Reaction mechanism for the conversion of $\gamma$-Valerolactone (GVL) over a Ru catalyst: a first-principles study. Ind Eng Chem Res 56:3217-3222. https://doi. org/10.1021/acs.iecr.7b00196

38. Gao J, Wang Y, Ping Y et al (2012) A thermodynamic analysis of methanation reactions of carbon oxides for the production of synthetic natural gas. RSC Adv 2:2358. https://doi.org/10.1039/c2ra0 0632d

39. Takeda Y, Nakagawa Y, Tomishige K (2012) Selective hydrogenation of higher saturated carboxylic acids to alcohols using a $\mathrm{ReOx}-$ $\mathrm{Pd} / \mathrm{SiO} 2$ catalyst. Catal Sci Technol 2:2221. https://doi.org/10.1039/ c2cy20302b

40. Ayoub PM, Lange J-P (2008) Process for converting levulinic acid into pentanoic acid. WO 2008/142127 A1. https://world wide.espacenet.com/publicationDetails/originalDocumen $\mathrm{t}$ ?FT $=\mathrm{D} \&$ date $=20081127 \& \mathrm{DB}=\&$ locale $=\& C C=\mathrm{WO} \& \mathrm{NR}=20081$ 42127A1\&KC=A1\&ND=4\#. Accessed 28 Sept 2018

41. Lange JP, Price R, Ayoub PM et al (2010) Valeric biofuels: a platform of cellulosic transportation fuels. Angew Chem 49:4479-4483. https://doi.org/10.1002/anie.201000655 
42. Srihiranpullop S, Praserthdam P (2004) A new approach of coke characterization on metal and support for $\mathrm{Pt} / \mathrm{Al} 2 \mathrm{O} 3$ by combination of $\mathrm{Al} 2 \mathrm{O} 3$ and $\mathrm{Pt} / \mathrm{SiO} 2$. Catal Today 93-95:723-727. https:// doi.org/10.1016/j.cattod.2004.06.067

43. Iino A, Cho A, Takagaki A et al (2014) Kinetic studies of hydrodeoxygenation of 2-methyltetrahydrofuran on a Ni2P/SiO2catalyst at medium pressure. J Catal 311:17-27. https://doi.org/10.1016/j. jcat.2013.11.002

44. Al-Shaal MG, Dzierbinski A, Palkovits R (2014) Solvent-free $\gamma$-valerolactone hydrogenation to 2-methyltetrahydrofuran catalysed by $\mathrm{Ru} / \mathrm{C}$ : a reaction network analysis. Green Chem 16:1358-1364. https://doi.org/10.1039/C3GC41803K

45. Cho A, Kim H, Ino A et al (2014) Kinetic and FTIR studies of 2-methyltetrahydrofuran hydrodeoxygenation on $\mathrm{Ni} 2 \mathrm{P} / \mathrm{SiO} 2$. J Catal. https://doi.org/10.1016/j.jcat.2014.07.021

46. Bond JQ, Martin Alonso D, West RM, Dumesic JA (2010) $\gamma$-Valerolactone ring-opening and decarboxylation over $\mathrm{SiO} 2 /$ $\mathrm{Al} 2 \mathrm{O} 3$ in the presence of water. Langmuir. https://doi.org/10.1021/ la101424a
47. Jenkins RW, Moore CM, Semelsberger TA et al (2016) The effect of functional groups in bio-derived fuel candidates. ChemSusChem 9:922-931. https://doi.org/10.1002/cssc.201600159

48. Faba L, Díaz E, Ordóñez S (2014) Hydrodeoxygenation of acetonefurfural condensation adducts over alumina-supported noble metal catalysts. Appl Catal B Environ 160-161:436-444. https://doi. org/10.1016/j.apcatb.2014.05.053

49. Jenkins RW, Moore CM, Semelsberger TA, Sutton AD (2017) Heterogeneous ketone hydrodeoxygenation for the production of fuels and feedstocks from biomass. ChemCatChem 9:2807-2815. https ://doi.org/10.1002/cctc.201601678

Publisher's Note Springer Nature remains neutral with regard to jurisdictional claims in published maps and institutional affiliations. 